\title{
FORMULATION AND EVALUATION OF SYNTHESIZED QUINAZOLINONE DERIVATIVE FOR COLON SPECIFIC DRUG DELIVERY
}

\author{
SHAMMIKA P, ANEESH TP*, VIDYA VISWANAD*
}

Department of Pharmaceutics, Amrita School of Pharmacy, Amrita University, Amrita Vishwa Vidyapeetham, AIMS Health Sciences Campus, Kochi, Kerala, India. Email: vidyaviswanad@aims.amrita.edu, aneeshtp@aims.amrita.edu

Received: 03 November 2016, Revised and Accepted: 02 December 2016

\section{ABSTRACT}

Objective: The current research deals with the formulation and evaluation of synthesized quinazolinone derivative for colon site specific delivery.

Methods: The synthesized quinazolinone derivative was enteric coated 5\% Eudragit L-100 with by wet granulation method using guar gum, pectin, and guar gum pectin combination as hydrophilic polymer. The prepared matrix tablet was characterized by differential scanning calorimetry and evaluated for different pre-compression and post-compression studies and drug release profiles.

Results: All the matrix tablets were within the range of pharmacopeial limits with better flow properties. All the six formulations of matrix tablets had disintegrated within 5-6 minutes. The optimized formulation selected was F6 formulation combination of guar gum and pectin with 95.79\% of drug release than compared to the remaining formulation. The optimized matrix tablets followed zero order kinetics with Fickian diffusion.

Conclusion: The results proposed that the combination of guar gum and pectin coated tablet with $5 \%$ Eudragit L-100 of synthesized quinazolinone derivative is a promising colon site specific delivery.

Keywords: Quinazolinone derivative, In vitro drug release, Disintegration time, Guar gum, Pectin, 5\% Eudragit L-100, Colon site-specific delivery, Wet granulation, Compression.

(C) 2017 The Authors. Published by Innovare Academic Sciences Pvt Ltd. This is an open access article under the CC BY license (http://creativecommons. org/licenses/by/4. 0/) DOI: http://dx.doi.org/10.22159/ajpcr.2017.v10i3.16024

\section{INTRODUCTION}

From the last 20 years, an intensive quantity of analysis work has been administered within the space for colon site specific delivery attributed to its macromolecule and amide medicine that reduces the adverse effects within the treatment of colonic diseases, so minimizing the intensive first pass metabolism of steroids and produces delayed drug absorption for the treatment of atrophic arthritis, angina and nocturnal bronchial asthma, etc. [1].

One of the approaches we tend to suggests within the advancement of colon specific delivery is the advantage of 7-chloro-3-(4-chlorophenyl)2-phenyl quinazolin-4(3H)-one derivative for colon delivery. The synthesized 7-chloro-3-(4-chlorophenyl)-2-phenyl quinazolin-4(3H)one derivative belongs to heterocyclic category of compounds exhibiting medicine and biological activities [2]. 7-chloro-3-(4-chlorophenyl)-2phenyl quinazolin-4(3H)-one inhibits thymidylate synthase receptor preventing the expansion of cancerous cells. It is been aimed towards designing a $\mathrm{pH}$ dependent polymer matrix tablets of 7-chloro-3-(4chlorophenyl)-2-phenyl quinazolin-4 (3H)-one in consideration with minimizing the drug release within the biological surroundings of stomach and intestine associated to confirm the major drug release within the colon resulting in better patient approval, higher drug therapy and all advantages of an efficient colon specific delivery [3-7]. The colon is attracting interest attributable to its longer retention time due to its ability to reinforce the absorption of lipophilic drugs. Oral administration primarily depends on the chemical science properties of the drug, and therefore, the nature of the compound. Hydrophilic polymers play a key role in formulating oral controlled release tablets attributable to its chemical compound material that swells, and therefore, the drug releases by diffusion [8]. Many polysaccharides such as chondroitin salt, xanthan gum, guar gum, cellulose, and enzyme had been studied for providing higher potency in colon delivery. Pectin and guar gum are refractory to gastric and intestinal enzymes but are completely degraded by the colonic microorganism enzymes to provide soluble oligogalacturonides. The aim of this study was to prepare colon site-specific tablets of 7-chloro-3-(4-chlorophenyl)-2-phenyl quinazolin-4 (3H)-one using Guar gum and pectin as matrix polymer that provides protection to the drug till it leaves the abdomen that is provided by $\mathrm{pH}$ scale dependent polymer, Eudragit L 100 and major drug release in bowel is avoided by providing $\mathrm{pH}$ dependent coating of Eudragit [9-14].

\section{MATERIALS AND METHODS}

Materials

Guar gum, pectin, microcrystalline cellulose (MCC), croscarmellose sodium, sodium starch glycollate, talc, magnesium stearate, Polaxamer 407, Eudragit L-100 were purchased from Nice Chemicals Pvt. Ltd. Kochi.

\section{Methods}

Preparation and characterization of synthesized quinazolinone matrix tablets

Wet granulation technique was used for the preparation of synthesized quinazolinone matrix tablets using hydrophilic polymer (guar gum, pectin and combination) as matrix forming agent in the ratio of $1: 3$ and 1:5 with 5\% Eudragit L-100 for enteric coating. All the ingredients, i.e., quinazolinone, MCC, croscarmellose sodium were mixed vigorously in a mortar and pestle. The powdered ingredients were allowed to dry at $60^{\circ} \mathrm{C}$ before sieve through $16 \#$. The granules then passed through sieve no. 22\#. Finally, the granules were lubricated with talc, aerosil and magnesium stearate. The characterization of prepared matrix tablet was done by differential scanning calorimetry (DSC) $[15,16]$. The composition of the matrix tablet was represented in Table 1. 
Table 1: Composition of synthesized quinazolinone matrix tablet

\begin{tabular}{lll}
\hline S. No. & Ingredients & Quantity (mg) \\
\hline 1 & QD-synthesized quinazolinone & 200 \\
2 & MCC & 64 \\
3 & Sodium starch glycollate & 10 \\
4 & Croscarmellose cellulose & 6 \\
5 & Aerosil & 4 \\
6 & Talc & 3 \\
7 & Magnesium stearate & 3 \\
\hline
\end{tabular}

\section{Precompression parameters}

Precompression parameters include the determination of bulk density, tapped density, compressibility no comma after compressibility index, and Hausner's ratio. Weighed amount of $10 \mathrm{~g}$ of granules were transferred into a $100 \mathrm{ml}$ measuring cylinder. Initial volume was noted before 100 times tapping. The final volume was measured. Bulk density, tapped density, compressibility index (Carr's index), and Hausner's ratio were calculated. A funnel was placed fixed to a height and $10 \mathrm{~g}$ of powder was added through it. The tip of the funnel should be adjusted so that it touches the powder heap [16-19].

Bulk density $\left(\mathrm{V}_{\mathrm{b}}\right)=$ Mass/bulk volume

Tapped density $\left(\mathrm{V}_{\mathrm{tb}}\right)=$ Mass $/$ tapped volume

Hausner's ratio=Tapped density/bulk density

Carr's index $=\frac{\text { Tapped density }- \text { bulk density }}{\text { Bulk density }} \times 100$

\section{Postcompression studies}

\section{Hardness/crushing strength test}

Monsanto hardness tester was used to measure the strength of the matrix tablet. It consists of a lower plunger which was kept in contact with the tablet. The thunderbolt of the plunger has been tuned before zero reading by forcing against a plunger until the tablet ruptured. The force applied was detected by a barrel when the spring has been compressed. Randomly selected tablets were selected to measure the mean and standard deviation values were calculated [20-25]

\section{Friability test}

About 10 tablets were weighed and placed in Roche friability chamber which was allowed for 100 revolutions to attain effects of abrasion and shock because the tablet drops by six inches from the chamber. The tablets were re-weighed [20-24].

$$
\% \text { Friability }=\frac{\text { Initial weight of tablet }- \text { Final weight of tablets }}{\text { Initial weight of tablets }} \times 100
$$

\section{Thickness of tablets}

Calibrated screw gauge was used to measure the thickness of the tablet. The value of the prepared matrix tablet should be such that each tablet must deviate from \pm 5 of the standard value [20-24].

\section{Weight variation test}

About 20 tablets were randomly selected, and the average weight of each tablet was noted to compare with the individual weight of each tablet as described by IP was followed [20-24].

Percentage deviation $=\left(\mathrm{X}-\mathrm{X}^{*} / \mathrm{X}\right) \times 100$

Where,

$\mathrm{X}$ - Actual weight of the tablet

$\mathrm{X}^{*}$ - Average weight of the tablet.

\section{Drug content}

About 20 tablets were powdered and weighed. The powder was then dissolved in ethanol and made up to $100 \mathrm{ml}$. The solution was mixed well and filtered. To make the solution up to a desired concentration, the solution was then diluted with each $10 \mathrm{ml}$ of the prepared solution with ethanol. The absorbance of the resulting solution was measured using ultraviolet (UV) spectrophotometer [20-24,26].

$\%$ Drug content =

Actual quinazolinone content in weight quantity matrix tablet

Theoretical amount of quinazolinone in matrix tablet $\times 100$

\section{Evaluation of matrix tablets}

In vitro disintegration studies

Disintegration apparatus consist of six test tubes in which one tablet was placed in each of six test tubes which were immersed in a $1 \mathrm{~L}$ beaker in the basket containing pH 6.8 buffer solution maintained at $37 \pm 0.5^{\circ} \mathrm{C}$ in such a way that the tablet settles $2.5 \mathrm{~cm}$ lower to the surface of the liquid. The time at which the tablet completely disintegrates was noted [27].

\section{In vitro dissolution studies}

USP Type II (paddle type) dissolution test apparatus was used to study the drug release for all the six formulations. The tablet has been placed in a beaker attached to a paddle containing $900 \mathrm{~mL}$ dissolution medium. The apparatus was maintained at $37 \pm 0.5^{\circ} \mathrm{C}, 100 \mathrm{rpm}$. At first, the tablet has been placed in $\mathrm{pH} 1.2$ which was then replaced with $\mathrm{pH} 7.4$ and pH 6.8 after 2 hrs as the average gastric emptying time. At each time interval of $2,5,6,8,10,12,14,16,18,20$ and 24 hrs. $5 \mathrm{ml}$ of the sample was pipetted out with the same amount been replaced with dissolution media to attain sink condition. The withdrawn samples were analyzed from the absorption maxima by UV spectroscopy, and the release kinetics were studied by fitting the data in different kinetic models [28-30].

\section{Stability studies}

The prepared matrix tablet was tested for stability study based on ICH guidelines. The stability condition was maintained under two temperature: At room temperature $30 \pm 2^{\circ} \mathrm{C}$ and $65 \pm 5^{\circ} \mathrm{C}$ relative humidity (RH) and accelerated conditions $40 \pm 2^{\circ} \mathrm{C}$ and $75 \pm 5^{\circ} \mathrm{C}$ RH in a stability chamber. The samples were collected at regular intervals of $0,2,3$ and 6 months and tested for visual assessment such as appearance and weight variation, hardness, thickness, friability, and drug content [31-33].

\section{RESULTS AND DISCUSSIONS}

\section{Characterization of synthesized quinazolinone matrix tablets}

The DSC thermograph of quinazolinone derivative in (Fig. 2) showed four endothermic peak at $60.14,84.68,140.11$ and $239^{\circ} \mathrm{C}$. The first peak indicates guar gum since their value corresponds to their melting point. The melting point $239^{\circ} \mathrm{C}$ indicate the compound and the one with $140.11^{\circ} \mathrm{C}$ indicate the presence of pectin. The result shows the presence of both the compound and the polymer indicating that the pure compound changed to amorphous form. The photograph of the prepared matrix tablet is represented in Fig. 1.

\section{Precompression studies}

From the results, the bulk density values indicate to be significant since the density were $<1.2 \mathrm{~g} / \mathrm{cm}^{3}$. From the experiments, the angle of repose for all the six formulations were $<40^{\circ}$ indicating good flow property. The compressibility index and Hausner's ratio for the granules also specify good flow properties of the powders. All the data obtained were compared with the standard criteria as revealed in IP with efficient flow properties and better compressibility for all the formulated tablets. The results were given in Table 2.

\section{Postcompression studies}

The various batches of the tablet hardness were found to be within limits indicating good tablet strength. It was observed that the hardness of the 
tablets was found within $4.23 \pm 1.48-5.61 \pm 1.54 \mathrm{~kg} / \mathrm{cm}^{2}$. The satisfactory crushing strength considered to be $4 \mathrm{~kg}$ for tablet. The thickness of tablets was found to be in the range of $4.21 \pm 0.65-4.39 \pm 0.68 \mathrm{~mm}$, respectively, which indicates its uniformity in all the formulations. The tablets friability considered to be satisfactory since the ranges were observed from $0.56 \pm 0.37$ to $0.69 \pm 0.34 \%$ indicating its mechanical

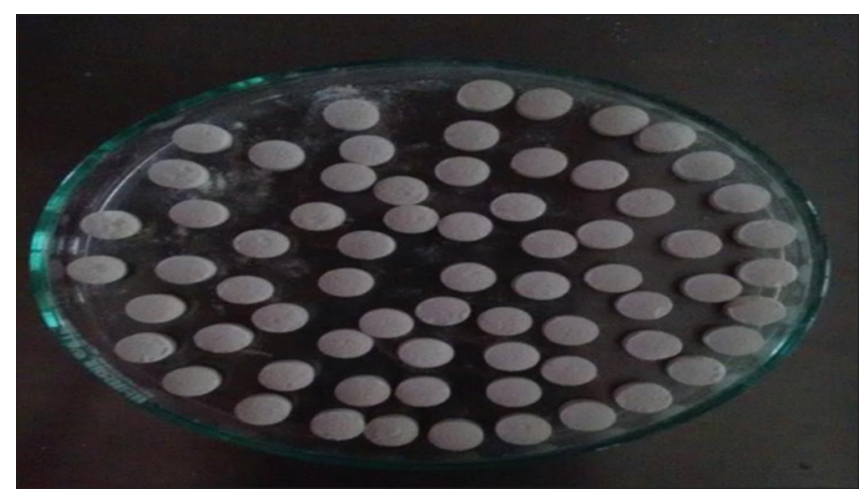

Fig. 1: Photograph of prepared matrix tablet stability with no broken tablets. The average weight of all the matrix tablet was in the range of $2.84 \pm 1.06-3.56 \pm 0.89 \mathrm{mg}$. The results of variation were $<7.5 \%$ within the pharmacopoeial limits indicating its uniformity with low standard deviation values. Drug content of the tablets was within $98.57 \pm 0.83-98.76 \pm 1.52$ which significantly approves the homogeneity of the drug and excipients. The results were given in Table 3.

\section{In vitro disintegration study}

In vitro disintegration studies were carried out for the matrix tablets. All the tablets were disintegrated within 5.21 $\pm 0.014-6.47 \pm 0.011$ minutes. The disintegration time for six formulations were shown in Table 4.

\section{In vitro drug release study}

For the productive delivery of drugs to the colon needs coating of drug from being released in abdomen and small intestine; hence the compression coated tablets were enteric coated to forestall the drug release in higher a part of stomach.

- All the tablets compression-coated with pH-dependent polymers (Eudragit L-100) showed low release percentage in $0.1 \mathrm{~N} \mathrm{HCl}$ for 2 hrs once the solution was replaced with phosphate buffer $\mathrm{pH} 7.4$ for another 3 hrs, F1 coated with Eudragit L100 exhibited the quickest release. It released $18.94 \%$ drug release of the drug in 3 hrs. On

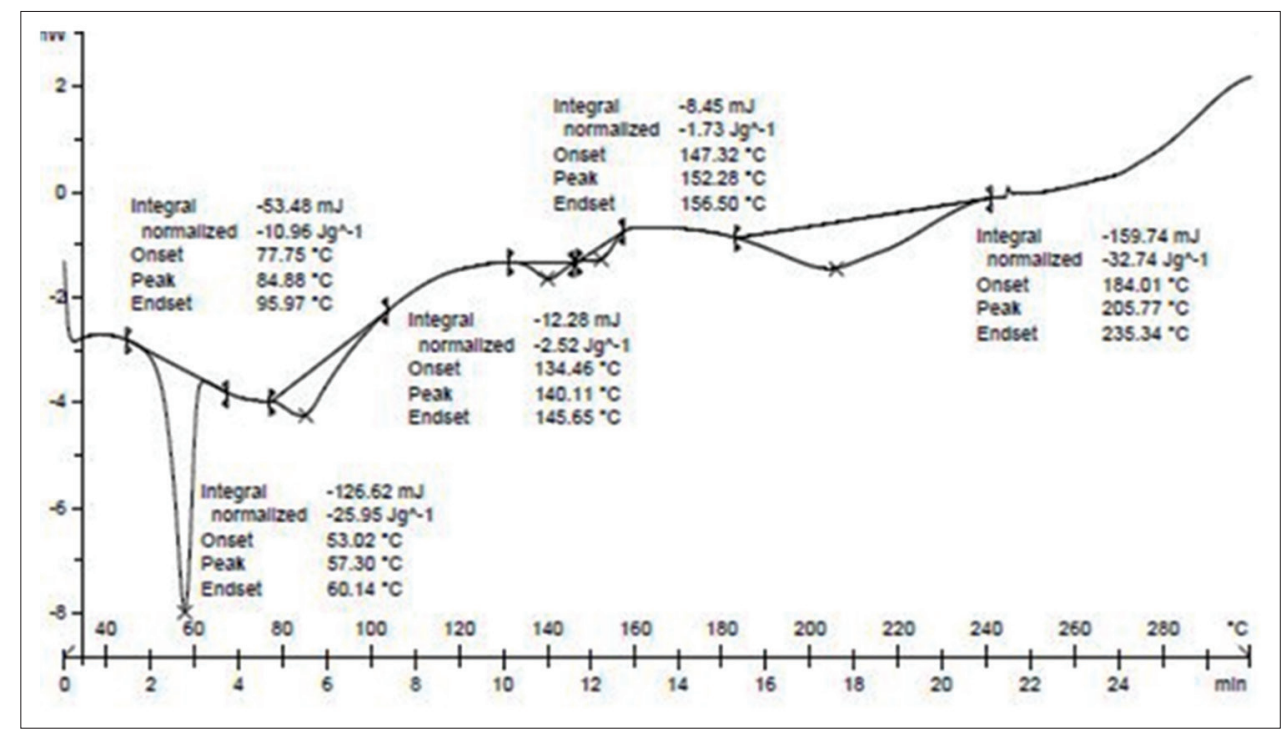

Fig. 2: Differential scanning calorimetry of prepared matrix tablet

Table 2: Precompression studies for the prepared matrix tablet

\begin{tabular}{llllll}
\hline Formulation code & Angle of repose $\left({ }^{\circ}\right)$ & Bulk density $(\mathrm{g} / \mathbf{c c})$ & Tapped density $\mathbf{( g / c c )}$ & Carr's index (\%) & Hausner's ratio \\
\hline F1 & $28.15 \pm 1.04$ & $0.584 \pm 0.013$ & $0.606 \pm 0.018$ & $10.05 \pm 0.58$ & $1.034 \pm 0.010$ \\
F2 & $29.86 \pm 1.06$ & $0.587 \pm 0.010$ & $0.610 \pm 0.017$ & $9.12 \pm 0.54$ & $1.038 \pm 0.012$ \\
F3 & $28.23 \pm 1.07$ & $0.575 \pm 0.014$ & $0.595 \pm 0.019$ & $9.84 \pm 0.63$ & $1.036 \pm 0.015$ \\
F4 & $29.25 \pm 1.08$ & $0.589 \pm 0.015$ & $0.613 \pm 0.013$ & $10.39 \pm 0.52$ & $1.047 \pm 0.011$ \\
F5 & $27.94 \pm 1.04$ & $0.590 \pm 0.013$ & $0.617 \pm 0.017$ & $10.14 \pm 0.67$ & $1.045 \pm 0.015$ \\
F6 & $28.36 \pm 1.02$ & $0.588 \pm 0.015$ & $0.616 \pm 0.017$ & $10.06 \pm 0.67$ & $1.036 \pm 0.014$ \\
\hline
\end{tabular}

All values are expressed in mean \pm standard deviation, $\mathrm{n}=3$

Table 3: Postcompression studies for the prepared matrix tablet

\begin{tabular}{|c|c|c|c|c|c|}
\hline Formulation code & Hardness $\left(\mathrm{kg} / \mathrm{cm}^{2}\right)$ & Thickness (mm) & Friability (\%) & Weight variation (mg) & Drug content (\%) \\
\hline F1 & $4.98 \pm 0.98$ & $4.21 \pm 0.65$ & $0.67 \pm 0.39$ & $3.49 \pm 0.88$ & $98.76 \pm 1.52$ \\
\hline $\mathrm{F} 2$ & $4.23 \pm 1.48$ & $4.25 \pm 0.54$ & $0.69 \pm 0.34$ & $3.56 \pm 0.89$ & $97.81 \pm 1.22$ \\
\hline F3 & $5.61 \pm 1.54$ & $4.37 \pm 0.62$ & $0.56 \pm 0.37$ & $3.48 \pm 1.06$ & $97.85 \pm 0.98$ \\
\hline F4 & $4.42 \pm 0.85$ & $4.28 \pm 0.49$ & $0.63 \pm 0.38$ & $2.99 \pm 1.08$ & $98.57 \pm 0.83$ \\
\hline F5 & $5.33 \pm 0.99$ & $4.39 \pm 0.68$ & $0.58 \pm 0.28$ & $3.24 \pm 1.06$ & $98.67 \pm 1.50$ \\
\hline F6 & $5.22 \pm 1.78$ & $4.22 \pm 0.52$ & $0.59 \pm 0.26$ & $2.84 \pm 1.06$ & $97.87 \pm 0.96$ \\
\hline
\end{tabular}

All values are expressed in mean \pm standard deviation, $n=3$ 
the other hand, F6 coated with Eudragit L-100 showed the slowest release in this medium where it released solely $0.64 \%$ release. The total percentage of the drug released in F1, F2, F3, F4, F5 and F6 were $78.43 \%, 81.68 \%, 83.29 \%, 83.29 \%, 86.68 \%, 93.66 \%$ and $95.79 \%$ release, respectively, after the $24 \mathrm{hrs}$ of the release study. Therefore, Eudragit L-100 prevents the release of the drug into stomach and small intestine by degrading the polymer into the microorganism enzymes of colon.

The formulations of different matrix tablets containing guar gum $(1: 3,1: 5)$

A maximum release of $71.43 \%$ and $73.66 \%$ drug release were shown by formulation F1 and F2 respectively. In case of tablet formulated with

Table 4: In vitro disintegration of matrix tablet

\begin{tabular}{ll}
\hline Formulation code & Disintegration time \\
\hline F1 & $5.21 \pm 0.014$ \\
F2 & $5.48 \pm 0.015$ \\
F3 & $6.12 \pm 0.012$ \\
F4 & $6.47 \pm 0.011$ \\
F5 & $6.22 \pm 0.014$ \\
F6 & $6.45 \pm 0.015$ \\
\hline All values are expressed in meantstandard deviation $\mathrm{n}=3$
\end{tabular}

All values are expressed in mean \pm standard deviation, $n=3$ guar gum, F1 and F2 show $6.28 \%$ and $6.10 \%$ drug release for $2 \mathrm{hrs}$ and $18.94 \%$ and $14.27 \%$ within 5 hrs

The formulations of two different matrix tablets containing for pectin $(1: 3,1: 5)$

The cumulative percentage released was then plotted against time and maximum release of $81.29 \%$ and $84.68 \%$ were shown by F3 and F4, respectively. F4 using 1:5 drug polymer ratio showed better drug release when compared to F3. It has been noted that as the concentration of pectin decreases the rate and extent of drug release increased. Hydration and swelling of pectin or guar gum result in the formation of a viscous gel layer. This in turn slows down the dissolution from the core tablet. Mechanical erosion of the swollen polymer takes place when the tablet gets hydrated, and the drug release takes place by diffusion of tablet.

The formulations of different matrix tablets containing guar gum and pectin gum combination $(1: 3,1: 5)$

A maximum release of $93.60 \%$ and $95.79 \%$ was shown by F5, F6, respectively. The extent of target area for the drug release is 5-24 hrs. As the combination of hydrophilic polymer hydrated more with the degradation of bacterial enzyme.

The optimized formulation selected was F6 formulation combination of guar gum and pectin since the drug release was found to be $95.79 \%$

Table 5: Drug release kinetics for optimized formulation

\begin{tabular}{llllll}
\hline Formulation code & Zero order $\mathbf{R}^{2}$ & First order $\mathbf{R}^{2}$ & Higuchi $\mathbf{R}^{2}$ & & \multicolumn{2}{c}{ Korsmeyer-peppas } \\
\cline { 3 - 6 } & & & $\mathbf{n}$ & 0.4362 & $\mathbf{R}^{2}$ \\
\hline F6 & 0.9881 & 0.9362 & 0.9657 & 0.9499 \\
\hline
\end{tabular}

Table 6: Stability studied for optimized matrix tablets

\begin{tabular}{|c|c|c|c|c|c|}
\hline Months & Hardness $\left(\mathrm{kg} / \mathrm{cm}^{2}\right)$ & Thickness (mm) & Friability (\% loss) & Weight variation (\%) & Drug content (\%) \\
\hline 2 & $7.8 \pm 0.30$ & $3.64 \pm 0.18$ & $0.48 \pm 0.16$ & $347 \pm 0.40$ & $98.57 \pm 0.28$ \\
\hline 3 & $7.8 \pm 0.21$ & $3.63 \pm 0.24$ & $0.48 \pm 0.17$ & $347 \pm 0.30$ & $98.57 \pm 0.30$ \\
\hline 4 & $7.7 \pm 0.35$ & $3.65 \pm 0.20$ & $0.47 \pm 0.20$ & $345 \pm 0.22$ & $98.57 \pm 0.36$ \\
\hline 5 & $7.7 \pm 0.32$ & $3.66 \pm 0.18$ & $0.46 \pm 0.18$ & $345 \pm 0.30$ & $98.54 \pm 0.30$ \\
\hline 6 & $7.7 \pm 0.31$ & $3.65 \pm 0.21$ & $0.46 \pm 0.18$ & $345 \pm 0.40$ & $98.54 \pm 0.30$ \\
\hline
\end{tabular}

All values are expressed in mean \pm standard deviation, $n=3$

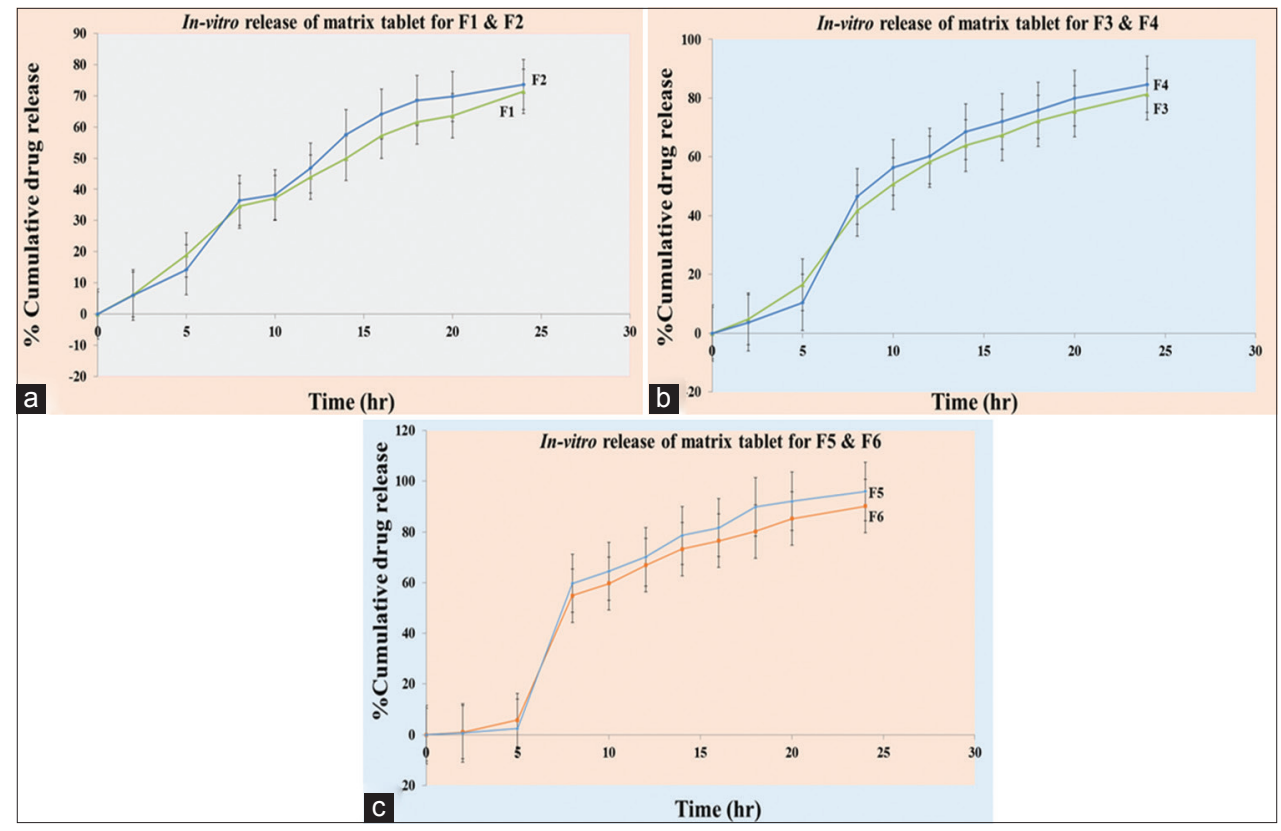

Fig. 3: (a) In vitro drug release for F1 and F2, (b) In vitro drug release for F3 and F4, (c) In vitro drug release for F5 and F6 


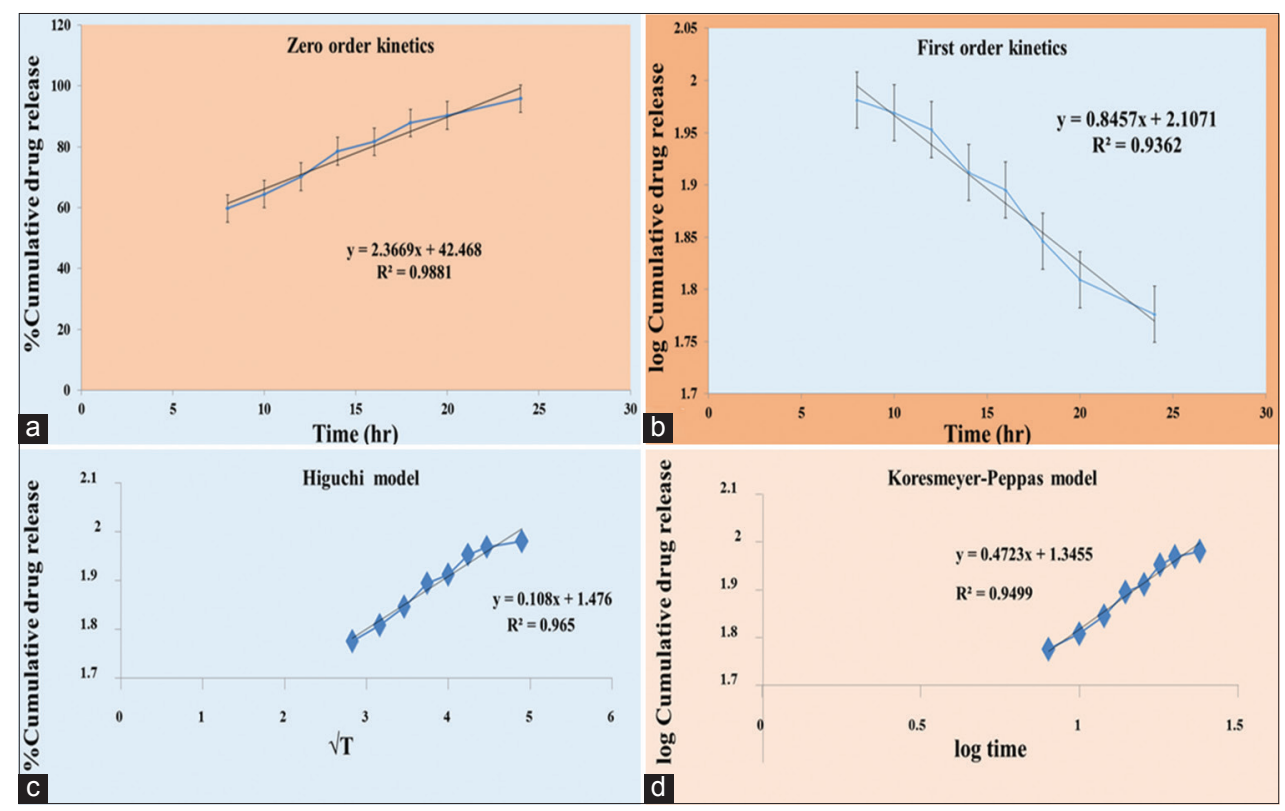

Fig. 4: (a) Zero order kinetics, (b) First order kinetics, (c) Higuchi model, (d) Koresmeyer-Peppas model

than compared to the remaining formulation. The release graph was represented in Fig. 3.

\section{Mathematical modeling of kinetics}

The kinetic modelling dissolution profile obtained were represented in Fig. 4 and the regression co-efficient value for the optimized formulation were mentioned in Table 5. Based on the in vitro release dissolution profiles and various dissolution parameters the best drug release from the tablet were selected from the formulation. The optimized formulation selected was F6.

The drug release followed zero order kinetics with Fickian diffusion mechanism as the regression coefficient has been greater in zero order.

\section{Stability studies}

The optimized formulation was found to be more stable for a period of 6-month based on ICH guidelines. The stability study profile for the optimized formulations were done for 6 months were represented in Table 6.

\section{CONCLUSION}

The formulated quinazolinone matrix tablet consist of guar gum, pectin as a polymer enteric coated with Eudragit L100 with main focus onto the release of drug into the colon. All matrix tablets possessed good hardness, friability, compression, disintegration, and dissolution properties. The guar gum-pectin combination matrix tablets were found to be more efficient drug release into the colon as the concentration of guar gum-pectin increased the release of drug into the stomach and intestine is decreased.

\section{REFERENCES}

1. Sinha VR, Kumria R. Colonic drug delivery: Prodrug approach. Pharm Res 2001;224(5):557-64.

2. Grover G, Kini SG. Synthesis and evaluation of new quinazolinone derivative of nalidixic acid as potential anticancer and antifungal agent. Eur J Chem 2007;42:1234-8.

3. Giri RS, Thaker HM. Design, synthesis and characterization of novel 2-(2,4-disubstututed-thiazole-5-yl)-3-aryl-3H-quinazoline-4-one derivatives as inhibitors of NF-kappa B and AP-1mediated transcription activation and as potential anti-inflammatory agents. Eur J Med Chem 2009;44:2184-9.

4. Kohli D, Hashim SR, Vishal S, Sharma M, Singh A. Synthesis and antibacterial activity of quinazolinone derivatives. Int J Pharm Pharm
Sci 2009;1(1):163-9.

5. Nagwa MA, Hanan HG, Riham MY, Nehad AE. Synthesis and antitumor activity of some 2, 3-disubstituted quinazolin-4(3H)-ones and 4,6-disubstituted-1,2,3,4-tetrahydroquinazolin-2H-ones. Eur J Med Chem 2010;45:6058-67.

6. Ye C, You J, Li XF, You R, Weng Y, Li J, et al. Design, synthesis and anticoccidial activity of a series of 3-(2-(2-methoxyphenyl)-2-oxoethyl) quinazolinone derivatives. Pesticide Biochem Physiol 2010;97:194-8.

7. Aly MM, Mohamed YA, El-Bayouki KA. Synthesis of some new 4(3H)quinazolinone-2-carboxaldehyde thiosemicarbazones and their metal complexes and a study on their anticonvulsant, analgesic, cytotoxic and antimicrobial activities. Eur J Med Chem 2010;45(8):3365-73.

8. Anjana MN, Joseph J, Nair SC. Solubility enhancement methods - Apromising technology for poorly water soluble drugs. Int J Pharm Sci Res 2013;20(2):127-34.

9. Ramprasad YV, Krishnaiah YS, Satyanarayana S. In vitro evaluation of guar gum as a carrier for colon-specific drug delivery. J Controlled Release 1998;59:281-7.

10. Kothawade PD, Gangurde HH. Conventional and novel approaches for colon specific drug delivery: A review. E-JST J Controlled Release 2011;6(2):33-56

11. Sinha VR, Kumria R. Microbially triggered drug delivery to the colon. Eur J Pharm Sci 2003;18:3

12. Khan MZ, Prebeg Z, Kurjakovic N. A pH dependent colon targeted oral drug delivery system using methacrylic acid copolymers: Manipulation of drug release using Eudragit L100-55 and Eudragit S 100 combinations. J Controll Release 2014;58:215-22.

13. Wajid S. Formulation and evaluation of colon targeted drug delivery system for antineoplastic drug. Int J Res Pharm Chem 2013;3(3):697-707.

14. Yang L, Chu JS, Fix JA. Colon-specific drug delivery: New approaches and in vitro/in vivo evaluation. Int J Pharm 2002;235(1-2):1-15.

15. Ashford M, Fell JT, Attwood D, Sharma H, Woodhead P. An evaluation of pectin as a carrier for drug targeting to colon. J Controlled Release 1993;26:213-220.

16. Aswar PB, Khadabadi SS, Kuchekar BS, Wane TP, Matake N. Development and evaluation of colon specific formulations for orally administered diclofenac sodium. Arch Pharm Sci Res 2009;1(7):48-53.

17. Ashutosh M, Parikh RK, Parikh MC. Formulation, development and evaluate; on of patient friendly dosage forms of metformin. Asian J Pharm 2008;2:177-81.

18. Singh BN. Modified-release solid formulations for colonic delivery. Recent Pat Drug Deliv Formul 2007;1(1):53-64.

19. Randall J. The colon as a site for drug delivery. J Controlled Release 1992;22:15-34.

20. Krishnaiah YS, Reddy PR, Satyanarayana V, Karthikeyan RS. Studies on the development of oral colon targeted drug delivery systems for metronidazole in the treatment of amoebiasis. Int J Pharm 
2002;236(2):43-55.

21. Wu B, Chen Z, Wei X, Sun N, Lu Y, Wu W. Biphasic release of indomethacin from HPMC/pectin/calcium matrix tablet: I. Characterization and mechanistic study. Eur J Pharm Biopharm 2007;67(3):707-14.

22. Liu X, Sun Q, Wang H, Zhang L, Wang JY. Microspheres of corn protein, zein, for an ivermectin drug delivery system. Biomaterials 2005;26(1):109-115.

23. Florey K, David WF. Analytical Profiles of Drug SubstancesIvermectin. New Delhi: Academic Press-Elsevier; 2005. p. 156-84.

24. Fatima L, Asghar A, Chandran S. Multiparticulate formulation approach to colon specific drug delivery: Current perspectives. J Pharm Pharm Sci 2006;9(3):327-38,

25. Jain HN, Patel KR, Kanzariya VR, Shah HN, Upadhyay UM. Formulation and evaluation of colon targeted matrix tablet of naproxen. Int J Pharm Pharm Sci 2014;6(8):183-6.

26. Vivekanandan K, Gunasekaran V, Jayabalan G. Design and evaluation of colon specific drug delivery of budenoside. Int J Pharm Pharm Sci 2015;7(1):261-3.
27. Takashi I. Design and evaluation of a new capsule-type dosage form for colon-targeted delivery of drugs. Int J Pharm 1998;87(5):31-40.

28. Dorozynski P, Jachowicz R, Jasinski A, Kulinowski P, Kwiecinski S, Skorka T, et al. The polymers for the preparation of hydrodynamically balanced systems: Methods of evaluation. Drug Dev Ind Pharm 2004;9(9):947-57.

29. Prasad YV, Krishnaiah YS, Satyanarayana S. In vitro evaluation of guar gum as a carrier for colon-specific drug delivery. J Controlled Release 1998;51(2-3):281-7.

30. Kotwal A. Design and evaluation of matrix-based controlled release tablets of diclofenac sodium and chondroitin sulfate. AAPS Pharm Sci Technol 2007;8(4):88

31. Umamaheswari RB, Jain S, Tripathi PK, Agrawal GP, Jain NK. Floating-bioadhesive microspheres containing acetohydroxamic acid for clearance of Helicobacter pylori. Drug Deliv 2002;9(4):223-31.

32. Nur AO, Zhang JS. Captopril floating and/or bioadhesive tablets: Design and release kinetics. Drug Dev Ind Pharm 2000;26(9):965-9.

33. Sruthy PN, Anoop KR. Formulation and evaluation of olmesartan medoxomil floating tablets. Int J Pharm Pharm Sci 2013;5(3):0975-1491. 